\title{
MODELOS DE CRECIMIENTO PARA Eucalyptus globulus EN MONTE BAJO ENTRE LAS REGIONES DE VALPARAISO Y LOS LAGOS
}

Juan Carlos Pinilla S.'

\section{RESUMEN}

Las plantaciones forestales en Chile alcanzan actualmente a 2,3 millones de hectáreas, están constituidas principalmente por pinos y eucaliptos y proveen casi la totalidad de la madera en trozas para fines industriales en el pais.

La superficie plantada con eucaliptos, fundamentalmente Eucalyptus globulus y Eucalyptus nitens, se ha más que sextuplicado desde principios de los 90 y actualmente representa algo más de un tercio de los bosques plantados del pais.

Las grandes empresas forestales emplean los eucaliptos fundamentalmente para produccion de pulpa, con fuerte silvicultura de establecimiento, sin manejo posterior, en corta rotación y solo en forma de monte alto.

Para pequeños y medianos propietarios, una silvicultura más intensiva, en rotación más larga, que ofrezca productos intermedios durante la rotación y madera de mayor valor al fin de esta, parece una alternativa interesante, y, en el caso de Eucalyptus globulus, rotaciones posteriores en monte bajo serian otra forma de mejorar la rentabilidad de estos cultivos forestales.

No existe por ahora suficiente información sobre los regimenes de manejo silvicola más adecuados a los cuales con estas especies, razón por la que el Instituto Forestal está desarrollando investigaciones sobre manejo en bosque alto y productos de mayor valor. especialmente para Eucalyptus nitens, y para manejo en monte alto y posterior monte bajo para Eucalyptus globulus. El presente trabajo entrega resultados obtenidos hasta ahora para el segundo de estos casos, entre las Regiones de Valparaiso y Los Lagos.

Palabras clave: Eucalyptus globulus, Monte Bajo, Manejo Forestal.

\section{SUMMARY}

Forest plantations area in Chile is currently 2.3 million hectares, mainly pines and eucalypts, and provides almost all the round wood for industrial purposes in the country.

The eucalypts planted area, mainly Eucalyptus globulus and Eucalyptus nitens, has increased more than six times from the 90's, and at current represents about one third of the

1-Instituto Forestal. Sede Bio Bio. Concepción, Chile. jpinilla@infor.cl 
planted forests in the country.

Big forest companies use eucalypts for pulp production, under intensive establishment treatments, without subsequent management, in short turns, and only under first growth forest regime.

A more intensive silviculture, in longer turns, that could offer intermediate products and higher value wood at the end, seems to be an interesting alternative for small and medium owners, and when Eucalyptus globulus is the species, subsequent turns under coppice regime would be another way to improve their incomes.

However, there is not enough information available on the appropriate silvicultural regimes for these species and that is the reason why the Chilean Forest Institute is carrying out research on first growth forest, for high value products in a longer turn, mainly with Eucalytus nitens, and first growth and coppice management with Eucalyptus globulus. This paper gives results from trials on the second between the Valparaiso and Los Lagos Regions.

Key words: Eucalyptus globulus, Coppice. Forest Managemen.

\section{INTRODUCCIÓN}

La superficie cubierta por especies del género Eucalyptus en Chile alcanza a 639 mil hectáreas y representa el $28 \%$ de la superficie total de plantaciones a nivel nacional. Predomina Eucalyptus globulus con 479 mil hectáreas y le sigue Eucalyptus nitens con 160 mil hectáreas (INFOR, 2008).

El incremento de las plantaciones de Eucalyptus en el pais ha sido considerable, en el año 1990 existia un total de unas 100 mil hectáreas, la tasa de plantación aumentó en forma importante a cifras en torno a las 50 mil hectáreas por año en los últimos años, e incluso en al año 2006, con 59 mil hectáreas, superó a Pinus radiata que registró 52 mil hectáreas (INFOR, 2008).

No contabilizadas dentro del total del género hay superficies menores de plantaciones de Eucalyptus camaldulensis, Eucalyptus cladocalyx, Eucalyptus sideroxylon, Eucalyptus tereticornis y otras, en la zona norte, y Eucalyptus regnans y Eucalyptus delegatensis, en la zona sur. El principal destino de las principales de estas especies es actualmente la producción de celulosa, polines y leña.

Las grandes empresas forestales en el pais establecen plantaciones de Eucalyptus globulus y Eucalyptus nitens para producción de pulpa principalmente, empleando plantas con material mejorado propagado en forma vegetativa (estaquillas), técnicas intensivas de establecimiento (preparación de suelos, fertilización inicial y control de competencia hasta segundo año), densidad de plantación de 1600 plantas por hectárea, sin manejo posterior, y rotaciones de 10 a 12 años, obteniendo rendimientos cercanos a los $200 \mathrm{~m}^{3} / \mathrm{ha}$.

En general se prefiere Eucalyptus globulus por la mayor densidad de su madera, que 
da una mayor rendimiento en pulpa. Eucalyptus nitens en tanto, es plantado en áreas de mayor altitud o mayor incidencia de heladas, donde la primera puede ser afectada, presenta muy buen crecimiento, pero la menor densidad de su madera, unos $50 \mathrm{~kg} / \mathrm{m}^{3}$ menos que Eucalyptus globulus, hace que el precio de la madera sea proporcionalmente más bajo.

Entre las alternativas silviculturales utilizadas en las plantaciones de Eucalyptus globulus en el pais, se encuentra el manejo de monte bajo, rodal regenerado vegetativamente por retoño proveniente del tocón o de la raiz dejada de la cosecha anterior. Esta alternativa en general no es empleada por las empresas grandes, principalmente debido a que en 10 a 12 años ya disponen de material genéticamente superior para iniciar una nueva plantación.

Empresas y propietarios pequeños y medianos, en tanto, prefieren en general Eucalyptus globulus, por el mayor precio de la madera, respecto de Euycalyptus nitens, y además porque esta última, si bien retoña en el pais, sus retoños no son lo suficientemente abundantes y vigorosos para asegurar un buen monte bajo, que para ellos representa una posibilidad de incrementar sus beneficios económicos, en cortas rotaciones, sin necesidad de reponer una plantación al fin de cada una de estas. Esto depende evidentemente del sitio, del manejo que se le dé al monte bajo, de la rotación y de los productos que se busque obtener.

El método de monte bajo es recomendable para productos de corta rotación, el volumen a obtener en una primera rotación en monte bajo suele ser superior al de la anterior en monte alto, el rendimiento de la segunda rotación en monte bajo suele igualar a la primera en monte alto, y en adelante es dificil que los brotes puedan superar en producción de madera a una nueva plantación (Ayling y Martins, 1981; Andrade et al., 1997; Camargo et al., 1997; González et al., 1997).

La opción de manejo en monte bajo, por su rápido crecimiento en rotación corta y su bajo costo de establecimiento, dado principalmente por clareo de los múltiples retoños que brotan de la cepa original, resulta muy interesante para obtener productos de valor en un menor número de años ( 8 a 10 años vs. 10 a 13 años monte alto) y acceder asi a diferentes escenarios económicos y de mercados (Pinilla, 2004).

Para productos de mayor valor, como madera, aserrada y chapas, se requieren indudablemente rotaciones más largas. Diversas experiencias de INFOR, en plantaciones experimentales con diferentes especies y procedencias de semillas de Eucalyptus, indican que en buenos sitios especies como, Eucalyptus nitens, Eucalyptus regnans y Eucalyptus delegatensis y Eucalyptus globulus muestran crecimientos medios de $77,63,50$ y $44 \mathrm{~m}^{3} / \mathrm{ha} /$ año, respectivamente, a los 15 años de edad en la costa de la Provincia de Arauco, siendo su crecimiento anual corriente a esa edad muy superior (Prado et al., 1986; Prado y Barros, 1989).

Experiencias similares con las mismas especies en la zona de Valdivia señalan un crecimiento anual corriente entre los 13 y 15 años muy alto, que en el caso de una procedencia australiana de Eucalyptus nitens llegan a casi $100 \mathrm{~m}^{3} / \mathrm{ha} /$ año (Barros, S., INFOR 2009 pers com.). 
Los antecedentes de crecimiento señalados en ensayos de INFOR corresponden a parcelas sin manejo, esto es sin podas ni raleos. La densidad inicial era de 2500 árboles por hectárea, por mortalidad natural a los 15 años registraban una densidad en torno a 2000 árboles por hectárea y volúmenes totales por sobre los $660 \mathrm{~m}^{3} / \mathrm{ha}$. Diámetros medios de $21 \mathrm{a}$ $24 \mathrm{~cm}$ indican claramente el exceso de competencia por la alta densidad. Estas plantaciones, bajo silvicultura intensiva, habrian mostrado a igual edad probablemente volúmenes totales semejantes, pero concentrados en un número muy inferior de árboles por hectárea (menos de la mitad) y con un valor comercial de la madera muy superior, además de haber ofrecido ciertos volúmenes de madera delgada para pulpa anteriormente en ocasión de los raleos.

La silvicultura de eucalipto en el pais a mayor rotación, para productos más valiosos y bajo un régimen silvicola intensivo, requiere aún de mayor investigación. INFOR está trabajando en esto, en especial con Eucalyptus nitens en la Región de Los Lagos (Cabrera, J., 2009 INFOR, pers com.).

En Portugal se mencionan crecimientos de 8 a $12 \mathrm{~m} / \mathrm{ha} / \mathrm{año}$, en rotaciones de 10 12 años, utilizando el manejo del monte bajo, y se señala que con una silvicultura intensiva (fertilización, riego) se pueden obtener hasta 4 rotaciones de 7 a 14 años cada una. En ese pais se ha desarrollado un acabado estudio del crecimiento de Eucalyptus globulus y, en especial, del manejo y rendimiento del monte bajo de esta especie (Pereira et al.. 1989; Tomé et al., 2001).

Para desarrollar, generar y promover productos que puedan ser demandados por los mercados tradicionales, es indispensable conocer el efecto de una serie de factores que están asociados al establecimiento de este tipo de oferta. Entre estos se cuentan un material genético adecuado, un buen manejo de los retoños, la edad de corta y el método de cosecha empleado, adicionalmente y dependiendo del sitio algunas prácticas de fertilización pueden resultar gravitantes también (INFOR, 2002).

Como se ha mencionado, las grandes empresas en general no aplican silvicultura de monte bajo, y pequeños y medianos propietarios y productores a menudo aplican la práctica comun en los campos del pais, en que antiguas cepas, irregulares y de gran tamaño, dan sucesivas y casi ilimitadas cosechas sin ningún manejo. En consecuencia, la información existente corresponde principalmente a los trabajos de INFOR, que avanzan en la validación de información de ensayos y en la cobertura de diferentes sitios del pais con parcelas experimentales.

De diferentes ensayos establecidos por INFOR se destacan y se coinciden en que basta con dejar uno o dos retoños por tocón para obtener la máxima ocupación de sitio y un buen rendimiento volumétrico, esto fundamentalmente por obtenerse diámetros superiores y un menor número de árboles por hectárea lo que influye a su vez en los costos y eficiencia de la cosecha final (Toral, 1988; Prado et al., 1990; Pinilla, 2004).

La capacidad de retoñación de Eucalyptus globulus, es normalmente muy buena, lo que se refleja en una gran cantidad de retoños por tocón y en el rápido crecimiento de estos. Existia información proveniente de algunas experiencias de INFOR (2002) y de algunos autores para 
casos especificos (Ribalta, E.; 1983; Diaz, F.; 1984; Peñaloza, S.; 1985; Toral, M. et al., 1988), por lo que era necesario obtener y validar mayor información sobre esta práctica silvicola, razón que motivó a INFOR a implementar una línea de investigación al respecto y se inició un estudio para desarrollar modelos de crecimiento para monte bajo de Eucalyptus globulus en el pais. Pinilla, et al (2007) entregan información preliminar y en el presente trabajo se presentan resultados con mayor elaboración y antecedentes.

El trabajo presenta los resultados de una segunda etapa de validación y ajuste de modelos de crecimiento y rendimiento, análisis en el que se contó con un mayor cantidad de información para el desarrollo de modelos de mortalidad natural, crecimiento en altura, área basal y volumen.

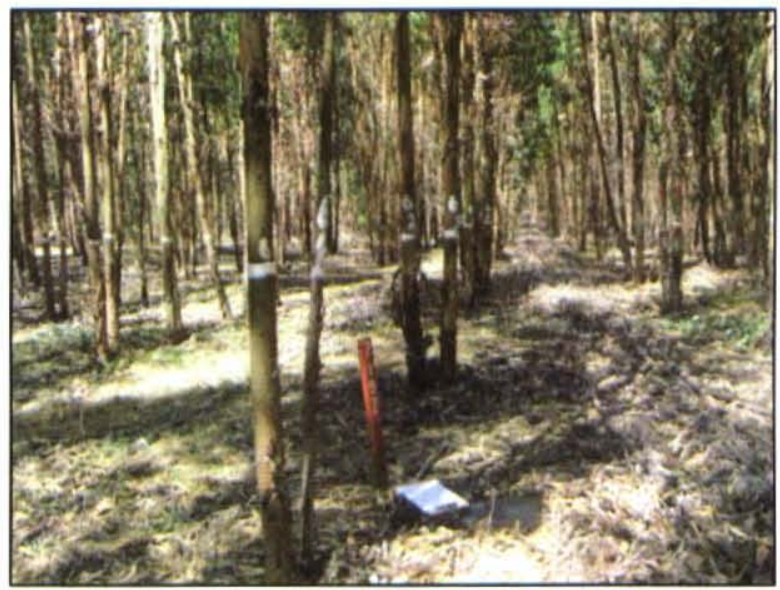

PARCELA PERMANENTE. SAN JAVIER, REGION DEL. MAULE

\section{OBJETIVOS}

Desarrollar y validar modelos de crecimiento y rendimiento para Eucalyptus globulus. bajo silvicultura de monte entre las Regiones de Valparaíso y Los Lagos, con el fin de entregar herramientas de apoyo para el manejo de de estos recursos en el pais, en especial a pequeños y medianos propietarios forestales.

\section{DESARROLLO MODELOS}

Disponiendo de mayor cantidad de información que en la etapa inicial del proyecto se desarrolló modelos de:

Crecimiento en altura

Mortalidad natural

Crecimiento y rendimiento para área basal

Área basal inicial 


\section{Crecimiento de área basal}

Predicción para volumen total

La información proviene de 38 parcelas permanentes y temporales de 1/20 de hectárea $\left(500 \mathrm{~m}^{2} 20 \times 25 \mathrm{~m}\right)$ instaladas en rodales de monte bajo distribuidos entre las Regiones de Valparaiso y Los Lagos, sobre las cuales se ha realizado un total de 185 mediciones dadas por controles periódicos de los parámetros de rodal realizadas en 2 a 4 oportunidades en cada una de ellas (Apéndice $N^{\circ} 1$ ). Estas parcelas están dentro del rango de edad 4 a 13 años, desde la corta del monte alto anterior (Figura $\mathrm{N}^{\circ} 1$ ).

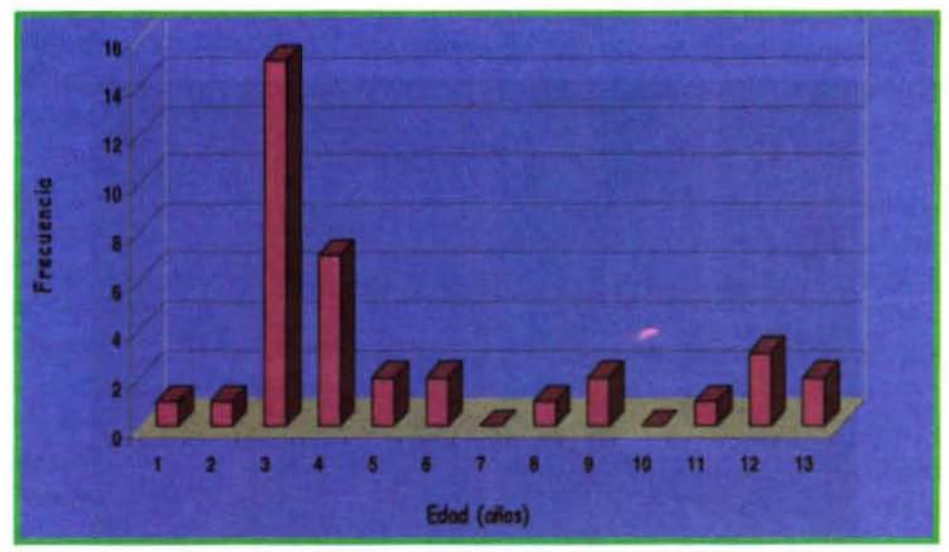

Figura $\mathrm{N}^{\circ} 1$

FRECUENCIA DE EDAD PARCELAS EXPERIMENTALES

Descripción de Los Rodales

Los parámetros medios del conjunto de parcelas experimentales son indicados en el Cuadro $\mathrm{N}^{\circ} 1$ y complementariamente se señalan los valore mínimos y máximos., en valores medios, mínimos y máximos.

\section{Cuadro $\mathrm{N}^{\circ} 1$ \\ PARÁMETROS GENERALES PARCELAS EXPERIMENTALES}

\begin{tabular}{|c|c|c|c|c|c|c|c|c|}
\hline Valores & $\begin{array}{c}\text { Mediciones } \\
\left(\mathbf{N}^{\circ}\right)\end{array}$ & $\begin{array}{c}\text { Altura } \\
\text { media } \\
(\mathbf{m})\end{array}$ & $\begin{array}{c}\text { DAP } \\
\text { Medio } \\
(\mathbf{m m})\end{array}$ & $\begin{array}{c}\text { voLuMEN } \\
\left(\mathbf{m}^{2} / \mathbf{h a}\right)\end{array}$ & $\begin{array}{c}\text { Área } \\
\text { Basal } \\
\left(\mathbf{m}^{2} / \mathbf{h a}\right)\end{array}$ & $\begin{array}{c}\text { Altura } \\
\text { Dominante } \\
(\mathbf{m})\end{array}$ & $\begin{array}{c}\text { Densidad } \\
(\text { arb/ha) }\end{array}$ & $\begin{array}{c}\text { Edad } \\
(\mathbf{a n n o s})\end{array}$ \\
\hline Medio & 2 & 10,2 & 75,9 & 39,40 & 8,56 & 12,3 & 1.667 & 4,1 \\
\hline Máximo & 4 & 26,3 & 215,1 & 278,01 & 29,34 & 30,3 & 3,660 & 19,4 \\
\hline Mínimo & 1 & 3,1 & 23,2 & 0,00 & 0,62 & 3,9 & 600 & 0,4 \\
\hline
\end{tabular}


La descripción de los rodales se presenta en una serie de gráficos en las figuras siguientes. Las Figuras $\mathrm{N}^{\circ}$ 2, 3 y 4 muestran los parámetros de Área Basal, Altura Dominante y Volumen, según edad, a la izquierda, y hasta 7 años de edad, a la derecha.
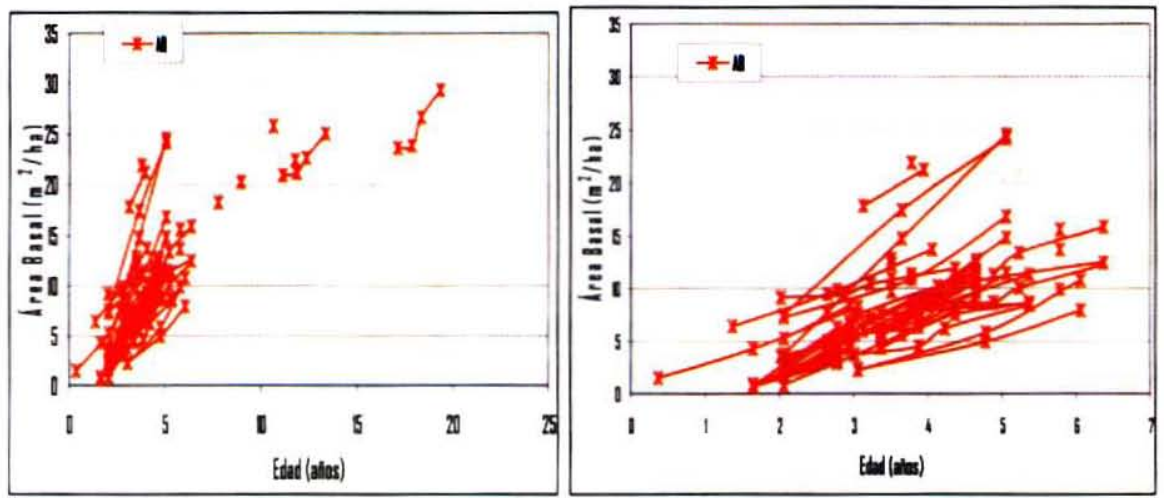

Figura $\mathrm{N}^{\circ} 2$

ÁREA BASAL SEGÚN EDAD MONTE BAJO
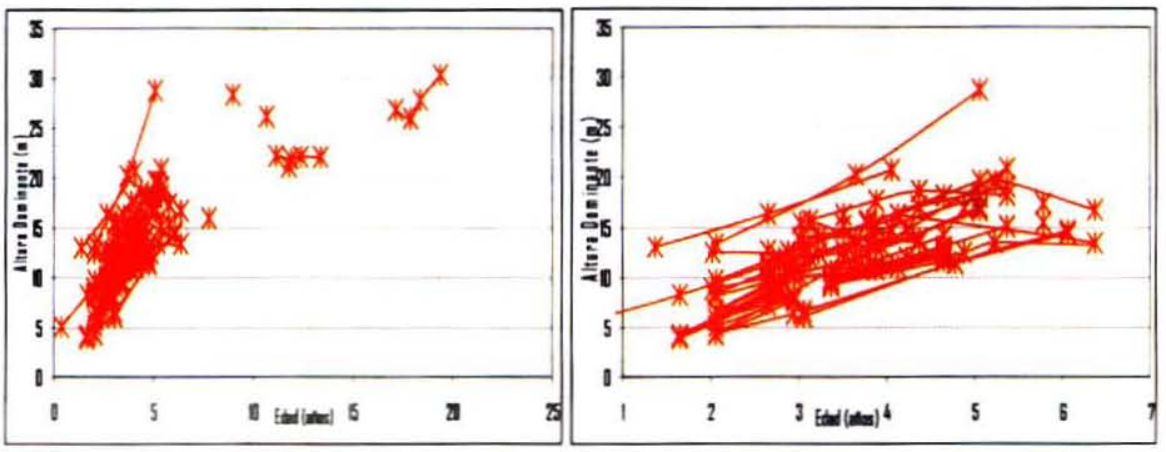

Figura $\mathrm{N}^{\circ} 3$

ÁLTURA DOMINANTE SEGÚN EDAD MONTE BAJO 

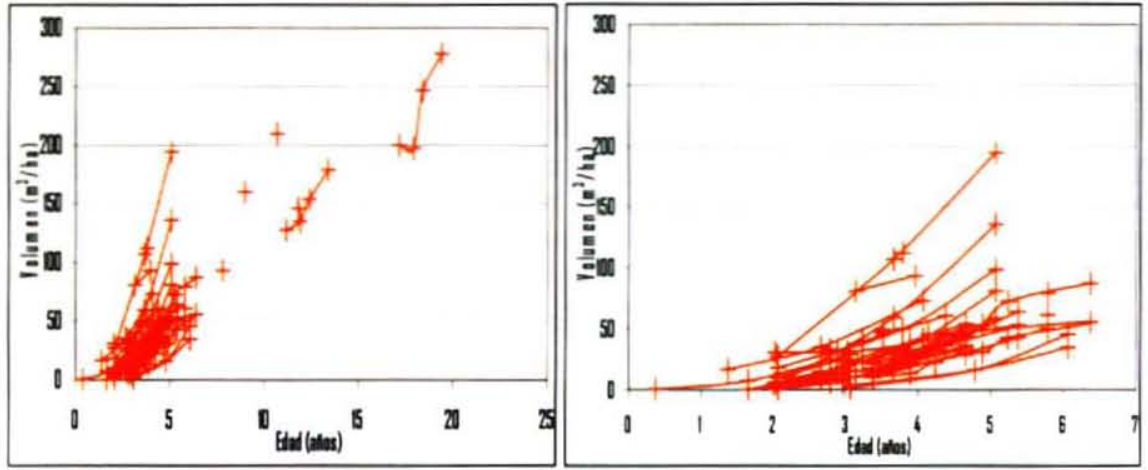

Figura $\mathrm{N}^{\circ} 4$

\section{VOLUMEN SEGÚN EDAD MONTE BAJO}

La Figura $N^{\circ} 5$ muestra las curvas Volumen - Área Basal y Altura - DAP para monte bajo del conjunto de parcelas experimentales.
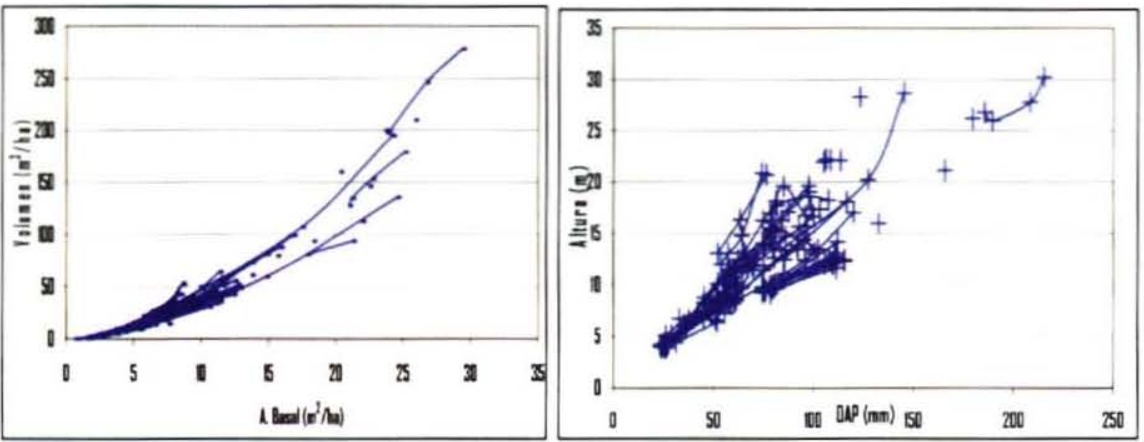

Figura $\mathrm{N}^{\circ} 5$

CURVAS VOLUMEN - ÁREA BASAL Y ALTURA - DAP PARA MONTE BAJO

En las Figuras $\mathrm{N}^{\circ} 6$ y 7 se muestra el comportamiento de los parámetros Altura Dominante y Área Basal, según edad para monte bajo, a la izquierda, y hasta 7 años de edad, a la derecha. Para efectos de comparación se incorpora información similar para monte alto, obtenida de otro conjunto de parcelas establecidas y evaluadas por INFOR dentro de esta linea de investigación. 

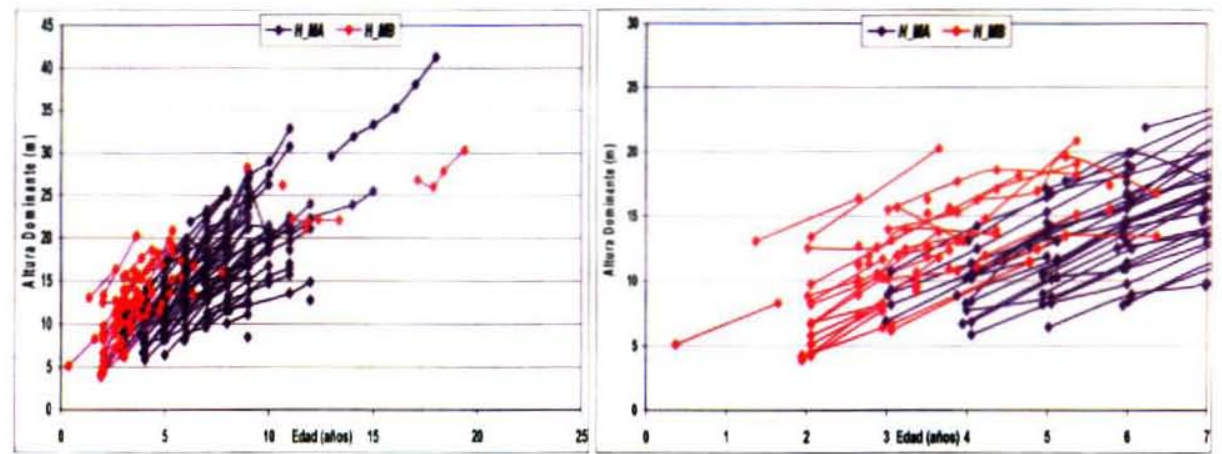

Figura $\mathrm{N}^{\circ} 6$

ALTURA DOMINANTE SEGÚN EDAD PARA MONTE BAJO (ROJO) Y MONTE ALTO (AZUL)
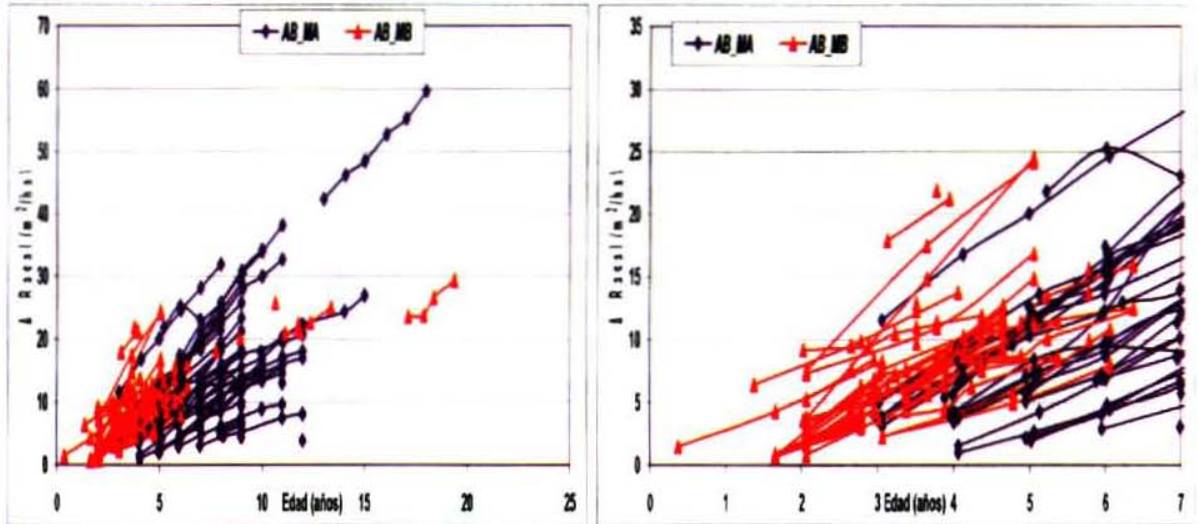

Figura $\mathrm{N}^{\circ} 7$

ÁREA BASAL SEGÚN EDAD PARA MONTE BAJO (ROJO) Y MONTE ALTO (AZUL)

En la Figura $\mathrm{N}^{\circ} 8$ se compara el comportamiento de la altura dominante según edad en monte bajo con Curvas de Índice de Sitio para monte alto ( 10 a $40 \mathrm{~m}$ para edad base 10 años). izquierda, y hasta 7 años, derecha. 

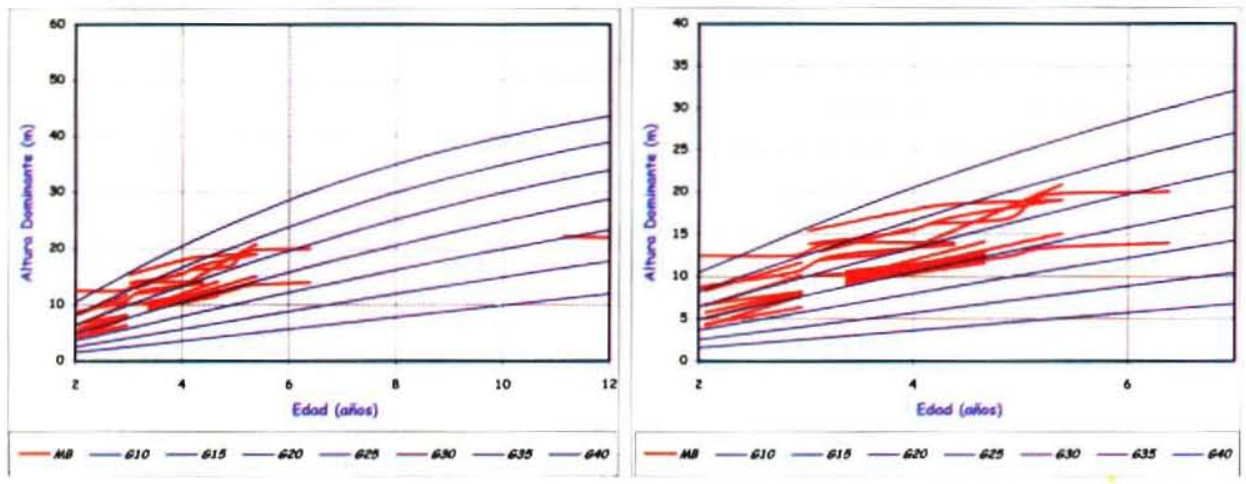

Figura $N^{\circ} 8$

ALTURA DOMINANTE SEGÚN EDAD PARA MONTE BAJO (ROJO) EN COMPARACIÓN CON CURVAS ÍNFICE SITIO (G) PARA MONTE ALTO (AZUL)

\section{Modelos Evaluados}

Los modelos y utilizados para realizar el nuevo ajuste son los que componen la planilla experimental de Crecimiento y Rendimiento, Euca3.2, para Eucalyptus globulus (Pinilla, 2006) y son los siguientes:

- Altura dominante

$H d=b_{0}^{*}\left\{1-\left(1-\left[S / b_{0}\right]^{\wedge} b_{1}\right)^{\wedge}[E / 10]\right\}^{\wedge}\left[1 / b_{1}\right]$

- Crecimiento en área basal

$G_{2}=\operatorname{EXP}\left(\left(E_{1} / E_{2}\right)^{\star} L O G\left(G_{1}\right)+a_{0}{ }^{*}\left(1-\left(E_{1} / E_{2}\right)\right)+a_{1}{ }^{\star} S^{\star}\left(1-\left(E_{1} / E_{2}\right)\right)\right)$

$G_{2}=\operatorname{EXP}\left(\left(E_{1} / E_{2}\right)^{*} L O G\left(G_{1}\right)+a_{0}{ }^{*}\left(1-\left(E_{1} / E_{2}\right)\right)+a_{1}{ }^{*} H d^{*}\left(1-\left(E_{1} / E_{2}\right)\right)\right)$

- Mortalidad natural (NAH o Número de árboles por hectárea)

$N_{2}=N_{1}\left(E_{2} / E_{1}\right)^{\wedge} b_{1} \operatorname{EXP}\left[b_{0}\left(E_{2}-E_{1}\right)\right]$

- Rendimiento para área basal

$G=\operatorname{EXP}\left[b_{1}+\left(b_{2} / E\right)\right]^{*}\left[N^{\wedge}\left(b_{3}+\left(b_{4} / E\right)\right)\right]^{*}\left[H d^{\wedge}\left(b_{5}+\left(b_{6} / E\right)\right)\right]$

- Rendimiento para volumen

$V=G\left[b_{0}+b_{1} H+b_{2}(N H) / G+b_{3}(1 / H d)\right]$ 
Donde:

$\mathrm{Hd}=$ Altura Dominante: Altura $(\mathrm{m})$ de los 100 árboles más gruesos a la edad $\mathrm{E}$.

$\mathrm{S}$ = Índice Sitio. Altura $(\mathrm{m})$ de los 100 árboles más gruesos a la edad de 10 años.

$E=\operatorname{Edad}$ (años).

$\mathrm{G}=$ Área Basal $\left(\mathrm{m}^{2} / \mathrm{ha}\right)$.

$\mathrm{G}_{2}=$ Area Basal $\left(\mathrm{m}^{2} / \mathrm{ha}\right)$ en $\mathrm{E}_{2}$.

$\mathrm{G}_{1}=$ Área Basal $\left(\mathrm{m}^{2} / \mathrm{ha}\right)$ en $\mathrm{E}_{1}$

$E_{2}=$ Edad 2 (años).

$E_{1}=$ Edad 1 (años).

$\mathrm{N}_{2}=$ Número de árboles por hectárea en $\mathrm{E}_{2}$.

$\mathrm{N}_{1}=$ Número de árboles por hectárea en $\mathrm{E}_{1}$.

$\mathrm{G}=$ Área basal $\left(\mathrm{m}^{2} / \mathrm{ha}\right)$.

$\mathrm{N}=$ Número de árboles por hectárea (arb/ha).

$\mathrm{V}=$ Volumen para un índice de utilización de $5 \mathrm{~cm}\left(\mathrm{~m}^{3} \mathrm{ssc} / \mathrm{ha}\right)$.

$a_{0}, a_{1}, b_{0}, b_{1}, b_{2}, b_{3}, b_{4}, b_{5}, b_{6}=$ coeficientes.

\section{Resultados Iniciales}

En el primer análisis realizado, testeando los modelos para monte alto de eucalipto en la situación de monte bajo (retoños), la mayor parte de los modelos de crecimiento o rendimiento existente no respondieron de buena forma, al estimar el crecimiento de las parcelas de monte bajo. Sólo el modelo de rendimiento en volumen, presentó un comportamiento aceptable en sus estimaciones. En tanto que el modelo de mortalidad natural, registró un sesgo hacia la sobreestimación de la mortalidad natural. En este análisis los modelos de área basal presentaron los sesgos y errores más altos, seguidos por el de altura dominante (Pinilla, 2006).

En aquel primer análisis se concluyó que posiblemente el crecimiento de los rodales de monte bajo presentan una dinámica diferente de crecimiento en relación a los rodales de monte alto. Dado que los modelos probados fueron desarrollados (sus coeficientes) solo con información de monte alto, estos no serian capaces de estimar correctamente el crecimiento de los retoños.

Durante el análisis también se señaló que un factor a considerar en la interpretación de los resultados obtenidos es la edad de las parcelas permanentes de monte bajo desde donde se obtuvo la información. En general, la estimación del crecimiento en edades bajas (menores a 5 años), como ha sido la situación inicial en este estudio, presenta un mayor grado de incertidumbre debido a lo irregular e inestable que es el crecimiento en ese rango de edad, más aún cuando se presentan elevadas tasas de crecimiento, como es el caso del monte bajo de eucalipto.

Una vez concluido que los modelos de monte alto no eran utilizables en el caso del monte bajo, se procedió a reajustar los modelos con la información obtenida desde los rodales de monte bajo. Este análisis generó en los casos de la altura dominante y mortalidad natural, una mejora 
significativa en los estadigrafos. Igualmente, se reajustaron los coeficientes de los modelos de área basal, de crecimiento y rendimiento, y de rendimiento en volumen. En general, las mejoras obtenidas para los modelos para monte bajo reajustados fueron significativas en comparación a la situación inicial. Nuevamente en este análisis la edad de los rodales y la cantidad de datos disponibles para los ajustes, generaron que los errores aleatorios de crecimiento en área basal y rendimiento en área basal fueron de 14 y $20 \%$, respectivamente, siendo deseable que este valor fuera menor al $15 \%$. La mejora fue significativa en los resultados de las estimaciones, en especial en el caso del volumen (Figura $\mathrm{N}^{\circ}$ 9), la altura dominante y la mortalidad natural.

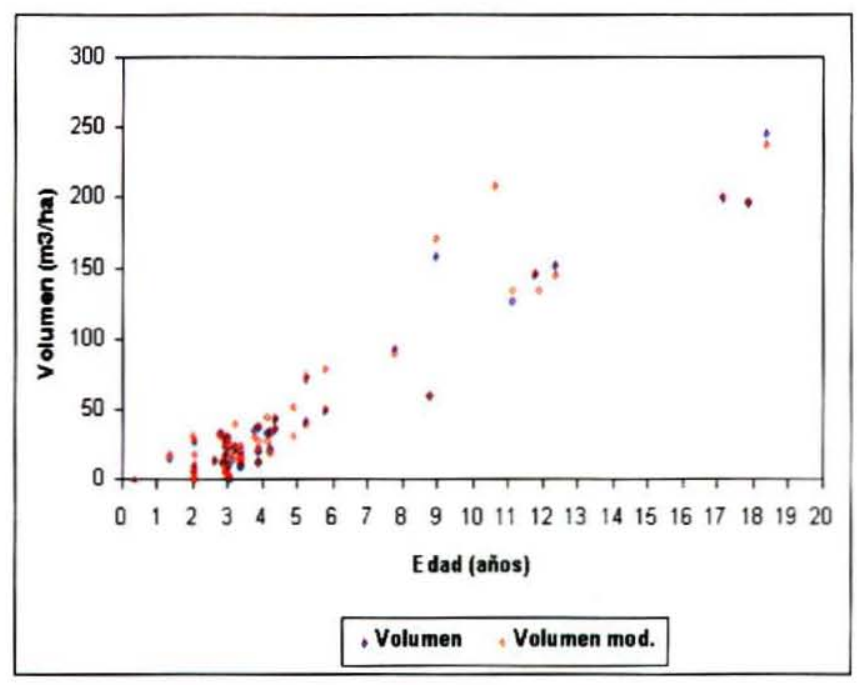

Figura $\mathbf{N}^{\circ} 9$

\section{ESTIMACIONES PUNTUALES Y SIMULACIÓN PARA RENDIMIENTO EN VOLUMEN MONTE BAJO (ROJO)}

Una vez establecido el monte alto, este superaria al monte bajo en crecimiento a partir de entre los 7 a 9 años, lo que se confirma con las asintotas de monte alto, las cuales son superiores que las de monte bajo. Para el caso del monte alto, se han obtenido asintotas en altura dominante cercana a los 60 metros, en tanto que el valor obtenido desde rodales de monte bajo alcanza a los 37 metros, lo cual señalaria un mayor potencial de crecimiento en altura del monte alto, mayor al extenderse la edad de los rodales. Lo que se registra desde la información de terreno, es que en los primeros años el monte bajo crece más rápido, pero luego sufre una baja del crecimiento, y essuperado por el monte alto.

El análisis de la información recopilada desde los diferentes rodales indica que el Índice de Sitio promedio estimado para Eucalyptus globulus de monte alto esta cercano a los 23 y 24 metros, en tanto que para monte bajo bordea los 21 metros. Estos Sitios son comparables o equivalentes, porque son las situaciones promedio para monte alto y monte bajo, respectivamente. Esta información permitió graficar las curvas de crecimiento en altura 
dominante y apreciar que el crecimiento en altura para monte bajo es mayor en un principio, pero luego es alcanzado por el crecimiento de monte alto, que tiene una proyección mayor en altura (Figura $\mathrm{N}^{\circ} 10$ ), cosa que ocurre a los 7 a 10 años de edad.

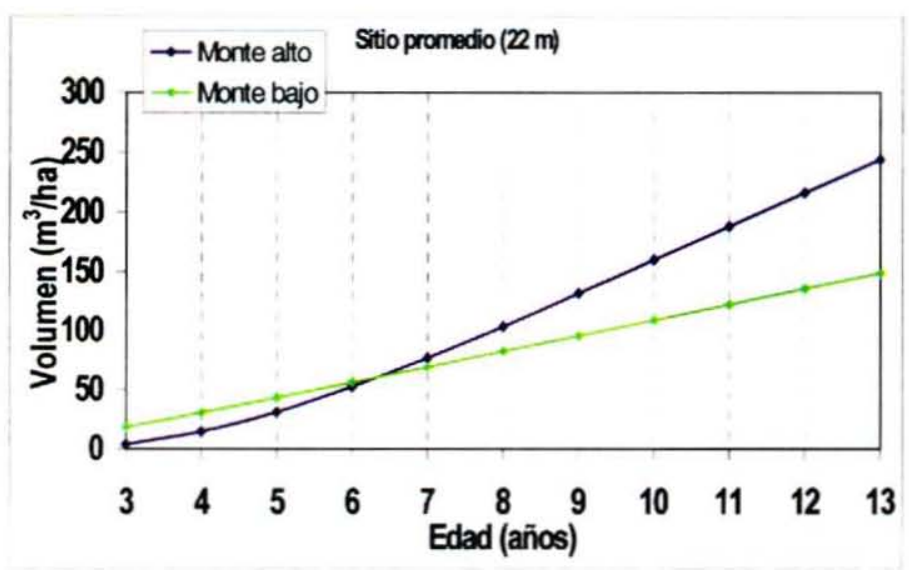

\section{Figura $\mathrm{N}^{\circ} 10$ \\ COMPARACIÓN DEL CRECIMIENTO DEL MONTE ALTO Y MONTE BAJO PARA UN SITIO PROMEDIO}

En este mismo análisis es necesario incluir el estudio del punto de quiebre en relación con la rentabilidad asociada a este tipo de manejo en relación con la entregada por el monte alto. En este análisis se debe considerar los costos de establecimiento y manejo, rendimientos volumétricos, rotaciones y precio del producto.

Si bien estas son estimaciones y aproximaciones, la evidencia hasta ahora señala que en promedio el monte alto supera al monte bajo en crecimiento de altura dominante a partir de los 10 años de edad.

Estos resultados deben ser además, analizados desde el punto de vista del análisis económico, la edad biológica de cruce de las curvas de crecimiento es entre 7 y 10 años, pero es necesario verificar la rentabilidad del monte bajo, más allá del punto de intersección de las curvas, debido al menor costo inicial o de establecimiento del monte bajo.

\section{EVALUACIÓN MODELOS}

\section{Crecimiento en Altura Dominante}

El principal problema encontrado para el modelo de crecimiento en altura dominante, al ser utilizado en estimaciones con la base ampliada con nuevas mediciones, fue un aumento considerable en el sesgo (DIFA\%), el que alcanzó un valor de $-6,8 \%$. 
Al realizar el nuevo ajuste de coeficientes con la base de datos ampliada se observa una baja en DIFA\%, pasando de $-6,8 \%$ a $-3,18 \%$, lo que representa una mejora. Sin embargo, si se comparan estos estadisticos con los del primer ajuste, realizado con base de datos original 2005, queda en evidencia que tanto DIFA\% como ECM\% aumentan sus valores (Cuadro $\mathrm{N}^{\circ}$ 2).

\section{Cuadro $\mathrm{N}^{\circ} 2$}

\section{COMPARACIÓN ENTRE LOS RESULTADOS DEL PRIMER AJUSTE Y EL NUEVO}

\begin{tabular}{|c|c|c|}
\hline Estadisticos & $\begin{array}{c}\text { Primer ajuste } \\
\text { Base datos original 2005 } \\
\text { (76 mediciones) }\end{array}$ & $\begin{array}{c}\text { Nuevo ajuste } \\
\text { Base datos ampliada 2008 } \\
\text { (161 mediciones) }\end{array}$ \\
\hline DIFA\% alt. dom. & 1,10 & $-3,18$ \\
\hline ECM\% alt. dom. & 8,32 & 10,72 \\
\hline
\end{tabular}

El hecho que ambos estadisticos hayan desmejorado sus niveles en el nuevo ajuste, en comparación con el primero, indica que las nuevas mediciones incorporaron aún mayor inestabilidad al total de mediciones existentes, cosa bastante lógica dado que la mayoria de las remediciones están en torno a los 5 años de edad. En este rango de edad el crecimiento es muy errático y aún poco definido. Es altamente posible que haya sido esta gran inestabilidad, aportada por las nuevas mediciones, la que ha influido en el deterioro de los estadisticos para los nuevos ajustes.

En la Figura $\mathrm{N}^{\circ} 11$ se presentan las curvas del modelo de altura dominante para el primer ajuste y el nuevo ajuste. La figura muestra que no hay diferencias significativas, a nivel gráfico, entre ambas curvas. 


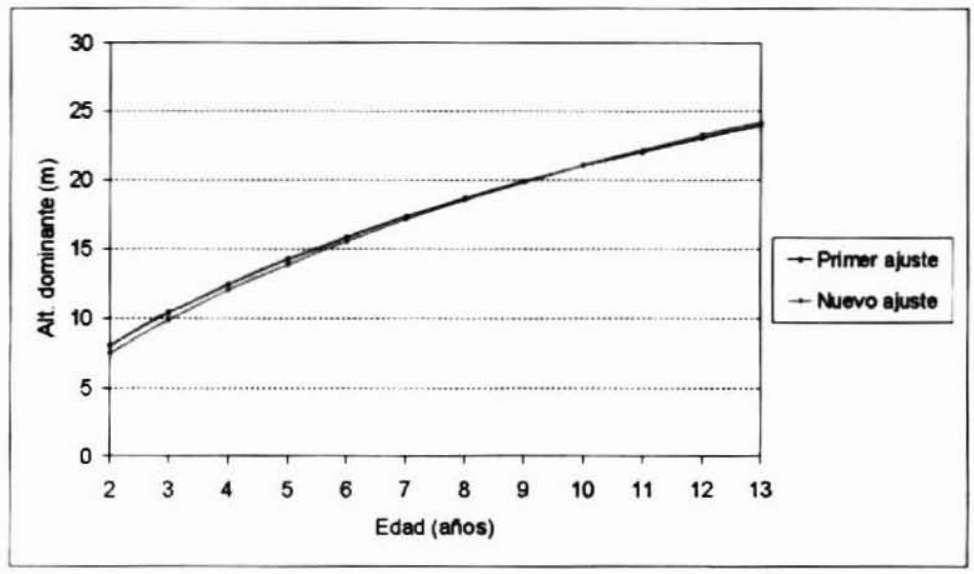

Figura $N^{\circ} 11$

COMPARACIÓN ENTRE CURVAS DEL PRIMER AJUSTE Y EL NUEVO AJUSTE (IS = 21)

El modelo y los coeficientes del nuevo ajuste son:

$H d=b 0^{*}\left\{1-\left(1-[S / b 0]^{\wedge} b 1\right)^{\wedge}[E / 10]^{\wedge}[1 / b 1]\right.$

Donde:

$\mathrm{Hd}=$ Altura Dominante. Altura $(\mathrm{m})$ de los 100 árboles más gruesos a la edad $\mathrm{E}$.

$\mathrm{S}=$ Indice de Sitio. Altura $(\mathrm{m})$ de los 100 árboles más gruesos a la edad de 10 años.

$E=E d a d(a n ̃ o s)$.

Modelo válido para edad en años: $2 \leq$ Edad $\leq 13$.

Coeficientes: $\quad$ b0 $=40,3$

$$
\mathrm{b} 1=1,367
$$

El coeficiente b0 representa la estimación de la asintota de crecimiento en altura dominante, es decir 40,3 metros. Cabe señalar que para el primer ajuste esta asintota fue de $37,7 \mathrm{~m}$. 


\section{Crecimiento en Área Basal}

Al igual que para el modelo de altura dominante, en el de crecimiento de área basal la incorporación de la base ampliada de mediciones aumentó considerable el sesgo de las proyecciones. La DIFA\% alcanzó un valor importante de $-13,95 \%$.

Al realizar el nuevo ajuste de coeficientes con la base de datos ampliada hay una baja muy importante en DIFA\%, pasando de $-13,95 \%$ a $-1,89 \%$, lo que representa una mejora sustancial. Sin embargo, y de la misma forma que se hizo para la altura dominante, si se comparan estos estadisticos con los del primer ajuste, queda en evidencia que tanto DIFA\% como ECM\% aumentan sus valores (Cuadro $\mathrm{N}^{\circ} 3$ ).

\section{Cuadro $\mathrm{N}^{\circ} 3$}

\section{COMPARACIÓN ENTRE LOS RESULTADOS DEL PRIMER AJUSTE Y EL NUEVO}

\begin{tabular}{|c|c|c|}
\hline Estadisticos & $\begin{array}{c}\text { Primer ajuste } \\
\text { Base de datos original 2005 } \\
\text { (76 mediciones) }\end{array}$ & $\begin{array}{c}\text { Nuevo ajuste } \\
\text { Base de datos ampliada 2008 } \\
\text { (161 mediciones) }\end{array}$ \\
\hline DIFA\% A. Basal & $-0,34$ & $-1,89$ \\
\hline ECM\% A. Basal & 14,34 & 19,8 \\
\hline
\end{tabular}

Ya comentado en el modelo de altura, en el caso del área basal también está el efecto de la inestabilidad adicionada por las nuevas mediciones. En la Figura $\mathrm{N}^{\circ} 12$ se presentan las curvas del modelo de crecimiento en área basal para el primer ajuste y el nuevo ajuste. La figura muestra que efectivamente hay diferencias significativas a nivel gráfico entre ambas curvas. Los nuevos coeficientes hacen que la curva de crecimiento en área basal pase por sobre la curva original, es decir, muestra un crecimiento mayor. Esto último tendrá impacto directo sobre la simulación del volumen, como se apreciará más adelante. 


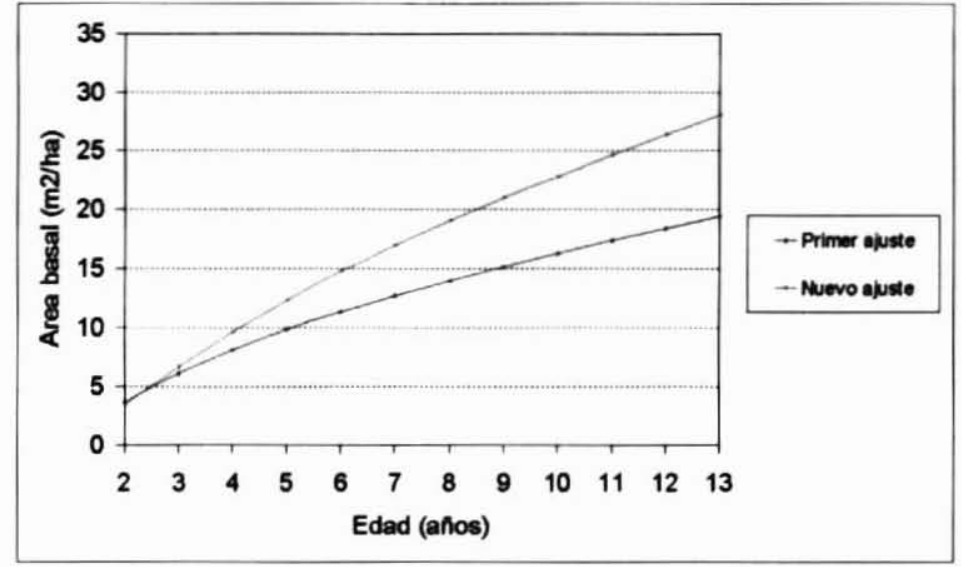

Figura $\mathrm{N}^{\circ} 12$

COMPARACIÓN ENTRE CURVAS DEL PRIMER AJUSTE Y EL NUEVO

(IS = 21)

El modelo y los coeficientes del nuevo ajuste son los siguientes:

$\mathrm{G} 2=\operatorname{EXP}\left((\mathrm{E} 1 / \mathrm{E} 2)^{*} \mathrm{LOG}(\mathrm{G} 1)+\mathrm{a} 0^{*}(1-(\mathrm{E} 1 / \mathrm{E} 2))+\mathrm{a} 1^{*} \mathrm{Hd}^{*}(1-(\mathrm{E} 1 / \mathrm{E} 2))\right)$

Donde:

$\mathrm{G} 2=$ Área basal $\left(\mathrm{m}^{2} / \mathrm{ha}\right)$ en $\mathrm{E} 2$.

$\mathrm{G} 1=$ Ärea basal $\left(\mathrm{m}^{2} / \mathrm{ha}\right)$ en $\mathrm{E} 1$.

$\mathrm{E} 2=\mathrm{Edad} 2$ (años).

$\mathrm{E} 1=\mathrm{Edad} 1$ (años).

$\mathrm{Hd}=$ Aaltura Dominante. Altura $(\mathrm{m})$ de los 100 árboles más gruesos a la edad $\mathrm{E}$.

Válido para edad en años: $2 \leq$ Edad $\leq 13$.

Coeficientes: $\quad \mathrm{a} 0=2,805$

$$
\mathrm{a} 1=0,055
$$

\section{Rendimiento en Área Basal}

Para el caso del modelo de rendimiento en área basal, se repite el mismo escenario que para el modelo de crecimiento en área basal, se obtiene una gran mejora para DIFA\%, de $-5,841 \%$ a $-0,221 \%$, pero al mismo tiempo se produce un aumento importante en ECM\%, de $20,179 \%$ a $28,384 \%$ cuando se comparan los nuevos ajustes con los primeros (Cuadro $\mathrm{N}^{\circ} 4$ ). Las causas de esto son las ya comentadas para altura dominante área basal. 


\section{Cuadro $\mathrm{N}^{\circ} 4$}

\section{COMPARACIÓN ENTRE LOS RESULTADOS DEL PRIMER AJUSTE Y EL NUEVO}

\begin{tabular}{|c|c|c|}
\hline Estadísticos & $\begin{array}{c}\text { Primer ajuste } \\
\text { Base de datos original 2005 } \\
\text { (76 mediciones) }\end{array}$ & $\begin{array}{c}\text { Nuevo ajuste } \\
\text { Base de datos ampliada 2006 } \\
\text { (161 mediciones) }\end{array}$ \\
\hline DIFA\% A. Basal & $-0,141$ & $-0,221$ \\
\hline ECM\% A. Basal & 20,179 & 28,384 \\
\hline
\end{tabular}

El modelo y los coeficientes del nuevo ajuste se presentan a continuación:

$\mathrm{G}=\operatorname{EXP}[\mathrm{b} 1+(\mathrm{b} 2 / E)]^{*}\left[\mathrm{~N}^{\wedge}(\mathrm{b} 3+(\mathrm{b} 4 / \mathrm{E}))\right]^{*}\left[\mathrm{Hd}^{\wedge}(\mathrm{b} 5+(\mathrm{b} 6 / \mathrm{E}))\right]$

Donde:

$\mathrm{G}=$ Área Basal $\left(\mathrm{m}^{2} / \mathrm{ha}\right)$.

$\mathrm{Hd}=$ Altura Dominante: Altura $(\mathrm{m})$ de los 100 árboles más gruesos .

$\mathrm{E}=\mathrm{Edad}$ (años).

$\mathrm{N}=$ Número de árboles por hectárea.

Modelo válido para edad en años: $2 \leq$ Edad $\leq 13$.

Coeficientes: $\quad b 1=2,465$

$b 2=-22,784$

b3 $=-0,151$

$\mathrm{b} 4=2,337$

$\mathrm{b} 5=0,603$

$\mathrm{b} 6=1,120$

\section{Rendimiento en Volumen}

En el caso del modelo de rendimiento en volumen sólo se registró un aumento moderado en el ECM\%, por lo tanto el reajuste del modelo era solo opcional. Aún asi, se efectuó un nuevo ajuste para los coeficientes con la base de datos ampliada, pero el nuevo ajuste no produjo ninguna mejora significativa en el ECM\%, de manera que no se justifica cambiar los actuales coeficientes del modelo.

Al realizar la simulación del crecimiento en volumen para un sitio promedio $(I S=21)$, como se muestra en la Figura $\mathrm{N}^{\circ} 13$, se observa que los nuevos coeficientes proyectan un crecimiento mayor para el volumen. Esto se debe casi totalmente a los nuevos coeficientes de la función de crecimiento en área basal (Figura $N^{\circ} 12$ ), que proyectan un crecimiento en área basal mayor que los primeros coeficientes. 


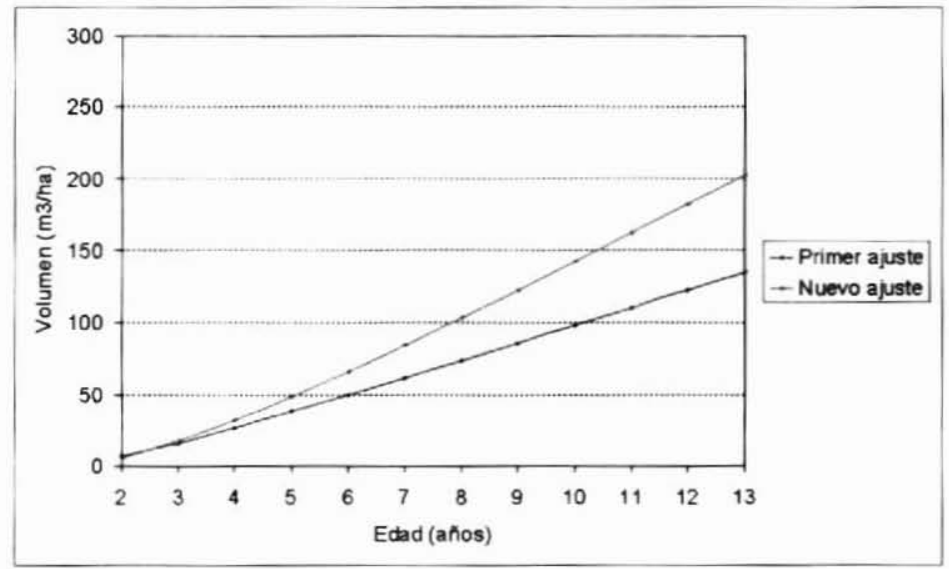

Figura $\mathrm{N}^{\circ} 13$

COMPARACIÓN ENTRE VOLUMEN SIMULADO CON COEFICIENTES DEL PRIMER AJUSTE Y DEL NUEVO

(IS = 21) continuación:

El modelo ajustado para monte bajo junto a sus coeficientes se presenta a

$V=G\left[b_{0}+b_{1} H+b_{2}(N H) / G+b_{3}(1 / H d)+b_{4}(H d / N)\right]$

Donde:

$V=$ Volumen para un indice de utilización de $5 \mathrm{~cm}\left(\mathrm{~m}^{3} \mathrm{ssc} / \mathrm{ha}\right)$.

$\mathrm{G}=$ Área Basal $\left(\mathrm{m}^{2} / \mathrm{ha}\right)$.

$\mathrm{Hd}=$ Altura Dominante. Altura $(\mathrm{m})$ de los 100 árboles más gruesos .

$N=$ Densidad (arb/ha).

Coeficientes: $\quad b_{0}=0,1884$

$$
\begin{aligned}
& b_{1}=0,2946 \\
& b_{2}=-0,0002 \\
& b_{3}=0,0 \\
& b_{4}=14,1097
\end{aligned}
$$

Las Figuras $\mathrm{N}^{\circ} 14$ y 15 confirman el adecuado desempeño de este modelo, mientras que en el Cuadro $\mathrm{N}^{\circ} 5$ se indica la mejora lograda en las estimaciones de rendimiento en volumen con este modelo, donde se aprecia mejoras tanto para la DIFA\%, como para el ECM\%. 


\section{Cuadro $\mathrm{N}^{\circ} 5$ \\ ESTADISTICOS MODELOS DE RENDIMIENTO EN VOLUMEN}

\begin{tabular}{|l|c|}
\hline \multicolumn{1}{|c|}{ Estadisticos } & Modelo para Monte Bajo \\
\hline Número Puntos & 156 \\
\hline Promedio Volumen $\left(\mathrm{m}^{3} / \mathrm{ha}\right)$ & 40,351 \\
Promedio Volumen estimado $\left(\mathrm{m}^{3} / \mathrm{ha}\right)$ & 40,431 \\
DIFA\% Volumen & 0,2 \\
ECM\% Volumen & 6,4 \\
\hline
\end{tabular}

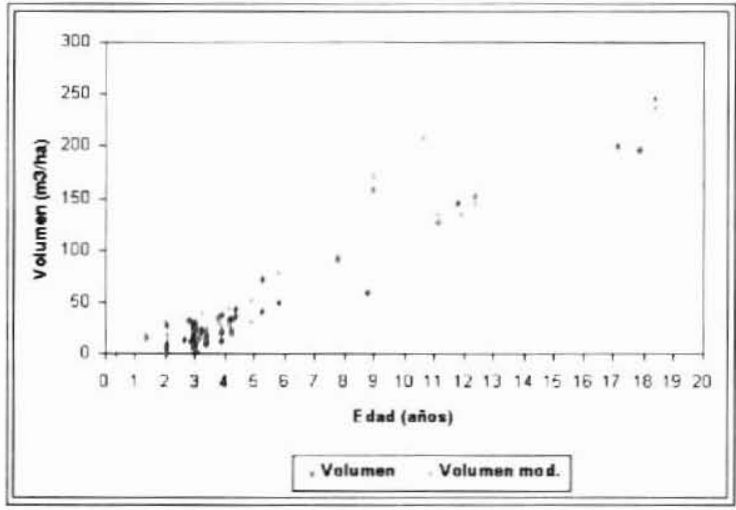

Figura $\mathrm{N}^{\circ} 14$

ESTIMACIONES PUNTUALES PARA RENDIMIENTO EN VOLUMEN

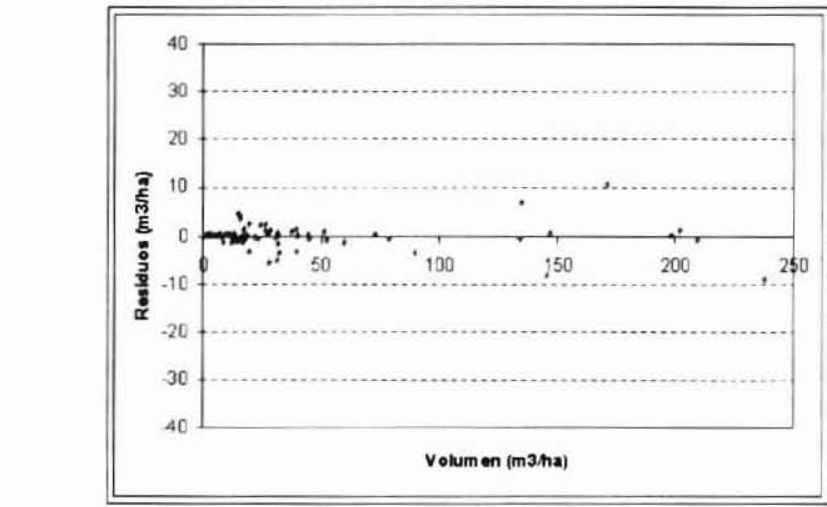

Figura $\mathbf{N}^{\circ} 15$

RESIDUOS (ESTIMADO - REAL) DE LAS ESTIMACIONES PUNTUALES DE RENDIMIENTO EN VOLUMEN 


\section{Mortalidad Natural}

Al igual que en el caso del modelo de volumen, para NAH o Número de árboles por hectárea, luego del nuevo ajuste no se detectaron variaciones en la eficiencia del modelo de Mortalidad Natural, entregando buenos resultados en esta nueva condición, ajustándose bien a los datos de monte bajo. continuación:

El modelo ajustado para monte bajo junto a sus coeficientes se presenta a $N_{2}=N_{1}\left(E_{2} / E_{1}\right)^{\wedge} b_{1} \operatorname{EXP}\left[b_{0}\left(E_{2}-E_{1}\right)\right]$

Donde:

$\mathrm{N}_{2}=$ Nủmero de árboles por hectárea en $\mathrm{E}_{2}$.

$\mathrm{N}_{1}=$ Número de árboles por hectárea en $\mathrm{E}_{1}$.

$\mathrm{E}_{2}=\mathrm{Edad} 2$ (años).

$E_{1}=\operatorname{Edad} 1$ (años).

Modelo válido para edad en años: $2 \leq$ Edad $\leq 15$.

Coeficientes: $\quad b_{0}=0,01465$

$b_{1}=-0,00758$

En Cuadro $\mathrm{N}^{\circ} 6$ se muestran los estadisticos que justifican el ajuste del modelo.

\section{Cuadro $\mathrm{N}^{\circ} 6$}

ESTADISTICOS MODELO MORTALIDAD NATURAL

\begin{tabular}{|l|c|}
\hline \multicolumn{1}{|c|}{ Estadisticos } & Modelo para Monte Bajo \\
\hline Promedio Densidad real (árboles/ha) & 1.853 \\
\hline Promedio Densidad estimado (árboles/ha) & 1.857 \\
\hline DIFA\% Densidad & 0,21 \\
\hline ECM\% Densidad & 0,68 \\
\hline
\end{tabular}

A continuacion (Figura $\mathrm{N}^{\circ} 16$ ) se presentan las estimaciones comparadas con series de datos reales, izquierda, y hasta 6 años de edad, derecha. 

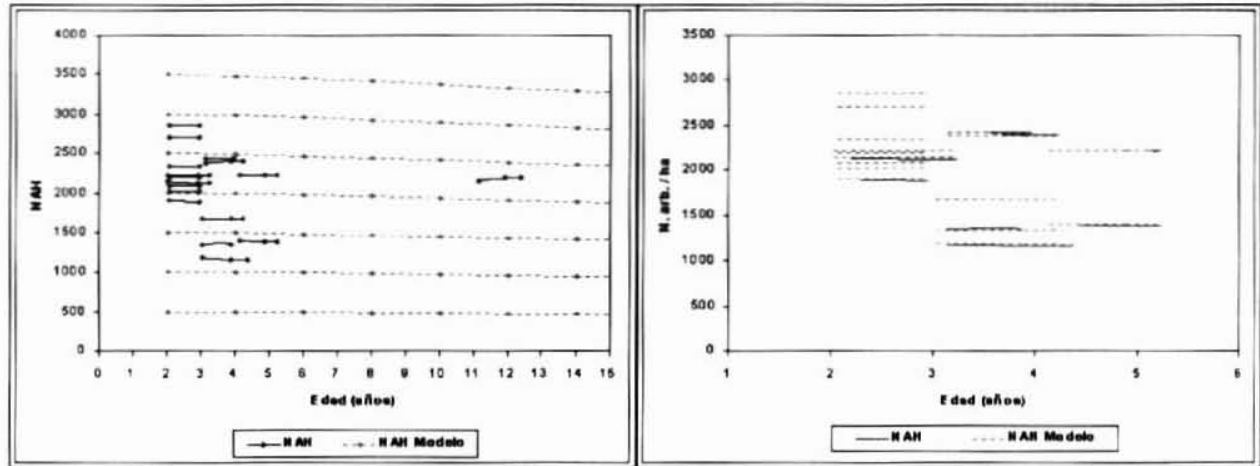

Figura $\mathrm{N}^{\circ} 16$

SIMULACIÓN CON MODELO PARA DIVERSAS DENSIDADES INICIALES VS SERIES DE DATOS REALES

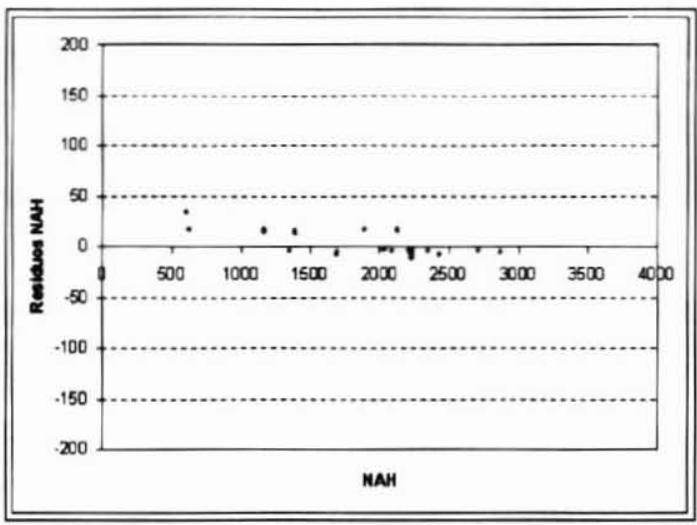

Figura $\mathbf{N}^{\circ} 17$

RESIDUOS (ESTIMADO-REAL) PARA LAS ESTIMACIONES DE MORTALIDAD NATURAL

\section{RECOMENDACIONES Y CONCLUSIONES}

En términos generales, si bien los nuevos ajustes de coeficientes redujeron el problema de sesgo negativo (problema de subestimación) identificado en el anterior análisis (Pinilla, 2006), por otro lado se produjo un aumento del ECM\% para la mayoria de las variables. Este deterioro en ECM\% se explica dado que las remediciones provienen de un rango de edad (en torno a los 5 años) que posee un patrón de crecimiento muy errático y poco definido, que es dificil de modelar.

Considerando lo anterior, la utilización de los nuevos coeficientes debería mantener niveles aceptables de sesgo, pero se producirá un aumento del ECM\%. 
El cambio más significativo se produce para los coeficientes del modelo de crecimiento en área basal, que proyectan valores mayores que los primeros coeficientes. Esto se ve reflejado directamente en la simulación del volumen, donde también se proyecta un crecimiento mayor.

Es necesario remarcar que es muy importante manejar con cautela estos modelos, son experimentales y para una amplia zona del pais. No es recomendable además, realizar estimaciones más allá de los 12 o 13 años.

Como se ha mencionado en anteriores análisis, existen grados de incertidumbre que solo podrán ser eliminados cuando se cuente con mayor número de mediciones en edades superiores, en especial cuando se cuente con información abundante en el rango de edad que va de los 6 a 15 años. Los modelos de monte bajo están fuertemente afectados por la edad de la información con que se cuenta.

Una vez reajustados los modelos con la base ampliada de información obtenida desde los rodales de monte bajo, se obtuvo una mejora significativa en los resultados de las estimaciones, en especial en el caso de la altura dominante y mortalidad natural.

Estos modelos son un paso más, su mejora será posible cuando se cuente con mayor número de mediciones y con una mayor densidad de estas para mayores rangos de edad, por lo que sin duda es necesario mantener la periodicidad de mediciones a fin de establecer si los resultados obtenidos hasta ahora se mantienen o varian en el tiempo y es necesario proceder a nuevos análisis y ajustes.

Como conclusiones se puede indicar que:

Los resultados de este trabajo permiten contar con herramientas iniciales de apoyo para el manejo eficiente del monte bajo de Eucalyptus globulus, que incluso permitiria la estimación de generación de biomasa con fines dendroenergético, aprovechando cortos ciclos de corta basado en el rápido crecimiento del monte bajo

Como es un trabajo pionero en esta materia en el pais, la información sobre la que se ha trabajado aún es limitada, siendo una aproximación que puede ser confirmada y probablemente mejorada cuando se puedan hacer ajustes con mayor cantidad de información.

Los nuevos ajustes de coeficientes al utilizar nueva información redujeron el problema de sesgo negativo (problema de subestimación), pero el nuevo ajuste produjo un aumento del ECM\% para la mayoria de las variables, explicado por las remediciones provienen de un rango de edad en torno a los 5 años, que posee un patrón de crecimiento variable, el cual es dificil de modelar.

Las mejoras obtenidas para los modelos para monte bajo reajustados fueron significativas en comparación a la situación inicial. 
Es imprescindible mantener la medición de unidades experimentales para aumentar la base de datos de trabajo y análisis, abarcando además otras áreas geográficas.

No es recomendable realizar estimaciones más allá de los 12 o 13 años.

\section{REFERENCIAS}

Andrade, H., Benedetti, V., Madaschi, J. y Bernardo, V., 1997. Aumento da produtividade da segunda rotação de eucalipto em função do método de desbrota. Serie Técnica IPEF (11) 30 : $105-116$.

Ayling, R.D., Martins, P.J., 1981. The growing of Eucalypts on short rotation in Brazil. Forestry Chronicle. 57(1): 9-16.

Camargo, F., Silva, C. y Stape, J., 1997. Resultados experimentais da fase de emissão de brotação em Eucalyptus manejado por talhadia. Serie Técnica IPEF (11) 30: 115 - 122.

Diaz C., F. 1984. Caracteristicas dendrométricas de Eucalyptus globulus (Labill) en la localidad de Colcura, Concepción. Tesis para optar al Grado de Ingeniero Forestal. Universidad de Chile. Facultad de Ciencias Agrarias, Veterinarias y Forestales. Santiago, Chile. 92p.

González-Rio, F., Castellanos, A., Fernández, O., Astorga, R. y Gómez, C., 1997. El cultivo del eucalipto. Manual práctico del selvicultor. http://agrobyte.lugo.usc.es/agrobyte/publicaciones/ eucalipto/indice.html Celulosas de Asturias S.A. Principado de Asturias. 95p.

INFOR, 2002. Documento proyecto "Incremento del negocio forestal a través de modelos de manejo y de gestión innovativa para la pyme forestal: la opción del monte bajo de Eucalyptus globulus". FONDEF-INFOR. Concepción, Chile.

INFOR, 2008. Anuario Forestal 2008. Boletin Estadistico №121. Santiago, Chile. 159p.

Peñaloza H., M., 1985. Funciones de volumen cúbico para la especie Eucalyptus globulus Labill. de monte bajo, en la Región Metropolitana. CONAF. Programa de Fomento y Desarrollo Forestal Región Metropolitana. CONAF. Boletín Técnico №25. Santiago, Chile. 74p.

Pereira, J.S., Linder, S., Araujo, M.C., Pereira, H., Ericsson, T., Borralho, N., Leal, L.C., 1989. Optimization of biomass production in Eucalyptus globulus plantations, a case study. Instituto Superior de Agronomia, Dept. of Forestry, Lisbon, Portugal. Proceedings of a NATO Advanced Research Workshop [Ed: Pereira, J.S.; Landsberg, J.J.]. 1989, 101-121; 31 ref. Series E, Applied Sciences 166. Dordrecht, Netherlands; Kluwer Academic Publishers.

Pinilla, J.C. 2004. Antecedentes generales acerca del manejo de monte bajo de Eucalyptus globulus. Proyecto INFOR-FONDEF Incremento del Negocio Forestal a Través de Modelos de Manejo y de Gestión Innovativa para la Pyme Forestal: La Opción del Monte Bajo de Eucalyptus globulus. Instituto Forestal, sede Bio Bio. Concepción, 2005. 44p. 
Pinilla, J.C., 2006. Estudio Inicial de Modelos de Crecimiento Para Monte Bajo de Eucalyptus globulus en Chile. Documento de Trabajo PMB-05, Proyecto FONDEF. 51p.

Pinilla, S., J.C., 2007. Eucalyptus globulus, La Opción del Monte Bajo. Sintesis de los resultados del proyecto FONDEF D0211117: incremento del negocio forestal a través de modelos de manejo y de gestión innovativa para la pyme forestal: la opción del monte bajo de Eucalyptus globulus. INFOR. Patrocinado por FONDEF Concepción, Chile, INFOR. 26p.

Prado, D., J.A., Barros, A., S., Wrann H., J., Rojas, V., P., Barros, R., D., Aguirre, A., S., 1986. Especies forestales exóticas de interés económico para Chile [monografias]. Santiago: INFOR. División Silvicultura, CORFO, $168 \mathrm{p}$.

Prado, D., J.A., Ed., Barros, A., S., Ed., 1989. Eucalyptus. Principios de silvicultura y manejo [monografias]. Santiago : INFOR. División Silvicultura, CORFO, 199p.

Prado, J.A., Bañados, J.C., Bello, A., 1990. The coppicing ability of some species of Eucalyptus in Chile. Instituto Forestal, Casilla 3085, Santiago, Chile. Ciencia e Investigación Forestal. 1990. 4: 2, 183-190; 3 ref.

Ribalta S., E., 1983. Evaluación de la producción y productividad del monte bajo de Eucalyptus globulus (Lab.), V Región. Tesis para optar al Grado de Ingeniero Forestal. Universidad de Chile. Facultad de Ciencias Agrarias, Veterinarias y Forestales. Santiago, Chile. 124p.

Tomé, M., Falçao, A., Carvalho, A., Amaro A., 1995. A Global Growth Model for Eucalypt Plantations in Portugal. Lensnictvi-Forestry, 41, 1995 (4): 197-205.

Tomé, M., Ribeiro, F. y Soares, P., 2001. O Modelo Globulus 2.1. Grupo de Inventario y Modelación de Recursos Forestales (GIMREF). Relatorios Técnico-cientificos do GIMREF. $N^{0} 1 / 2001$. Universidade Técnica de Lisboa, Instituto Superior de Agronomia, departamento de Engenharia Florestal. Lisboa, Portugal, 2001. 69p. más anexos.

Toral I., M., 1988. El efecto de diversas intensidades de clareo en el crecimiento de monte bajo de Eucalyptus globulus. En Actas Simposio manejo silvicola del género Eucalyptus. Viña del Mar, Chile. 9-10 Jun.1988. pp. 310-333. INFOR-CORFO.

Toral, M., Rosende, R., Pablo, G., 1988. Evaluación de raleos en monte bajo de Eucalyptus globulus (Labill) V Región. Revista Ciencia e Investigación Forestal 2(3): 2-11; 11 ref. Instituto Forestal, Santiago, Chile 


\section{APÉNDICE N¹}

1a. Descripción Rodales de Monte Bajo de Eucalyptus globulus

Series de Crecimiento en Volumen Según Edad

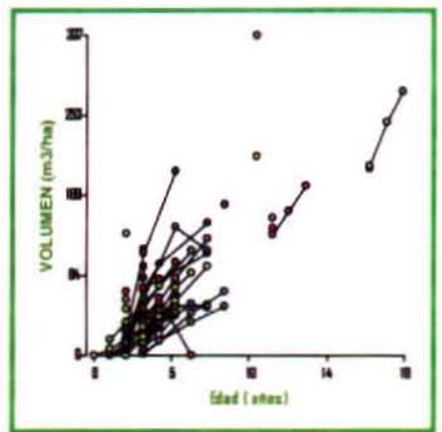

Volumen Según Edad

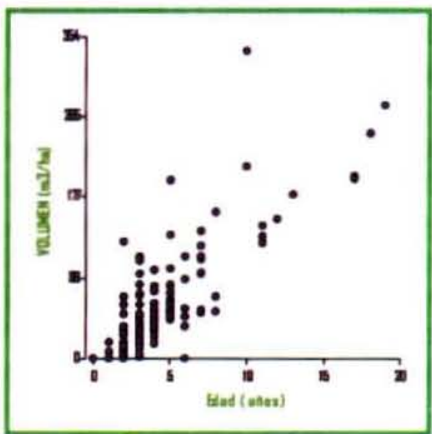

Relación Altura - Diámetro

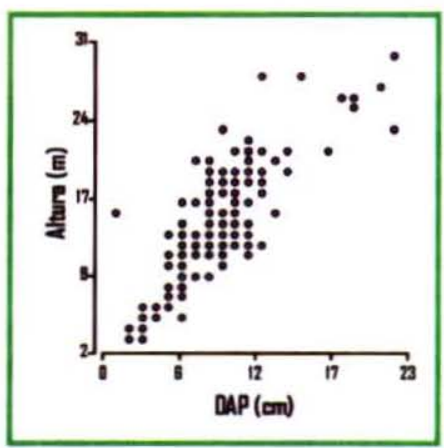


1b. Detalle Parcelas Experimentales Evaluadas de Monte Bajo de Eucalyptus globulus

\begin{tabular}{|c|c|c|c|c|c|}
\hline PARCELA & PROPIETARIO & AÑO & AREA & PREDIO & REGION \\
\hline 1 & CONAF V REGIÓN & 2000 & 500 & Peñuelas & V \\
\hline 2 & CONAF V REGIÓN & 2000 & 500 & Peñuelas & V \\
\hline 5 & IGNACIO ALLENDE & 2001 & 500 & $\begin{array}{c}\text { Sta. Marta de } \\
\text { Pullalli }\end{array}$ & V \\
\hline 102 & AGROBOSQUES VALDIVIA & 2001 & 500 & Pichoy & X \\
\hline 107 & JUAN PEDRO ANHUEZA & 2001 & 500 & El Retiro & X \\
\hline 716 & SOC. FORESTAL CANELILLOS LTDA. & 2000 & 1000 & La Montaña & VII \\
\hline 721 & SOC. FORESTAL CANELILLOS LTDA. & 2000 & 500 & Maromilla & VII \\
\hline 723 & FORESTAL CELCO & 2001 & 500 & Totorillas & VII \\
\hline 784 & RUBEN VILLAGRA & 2001 & 1000 & EI Membrillo & VII \\
\hline 793 & MADERAS PEREZ LTDA. & 2001 & 500 & Pangal de Reyes & VII \\
\hline 7106 & FORESTAL CELCO & 2003 & 500 & El Naranjo & VII \\
\hline 7107 & FORESTAL CELCO & 2002 & 500 & La Carmiña & VII \\
\hline 10000 & Propietario Particular & 2003 & 500 & Batral & VIII \\
\hline 10001 & Propietario Particular & 2003 & 500 & Batral & VIII \\
\hline 20000 & Propietario Particular & 1998 & 500 & Huacho & VIII \\
\hline 20001 & Propietario Particular & 2005 & 500 & Huacho & VIII \\
\hline 20002 & Propietario Particular & 2005 & 500 & Huacho & VIII \\
\hline 5 Testigo & IGNACIO ALLENDE & 2001 & 500 & Sta. Marta de & V Pullalli \\
\hline 716 Testigo & SOC. FORESTAL CANELILLOS LTDA. & 2000 & 1000 & La Montaña & VII \\
\hline 721 Testigo & SOC. FORESTAL CANELILLOS LTDA. & 2000 & 500 & Maromilla & VII \\
\hline 784 Testigo & RUBEN VILLAGRA-Testigo & 2001 & 1000 & EI Membrillo & VII \\
\hline
\end{tabular}




\section{1c. Ejemplo Detalle Base de Datos de Parcelas Experimentales Evaluadas de Monte Bajo de Eucalyptus globulus}

\begin{tabular}{|c|c|c|c|c|c|c|c|c|c|}
\hline PARC & MED & D_MAXIMO & D_MEDIO & VOLUMEN & $\overline{A B}$ & H_DOM_100 & $\mathrm{NAH}$ & NTOCH & EDAD \\
\hline 1 & 0 & 143,0 & 78,5 & 30,452 & 7,236 & 15,46 & 1340 & 1080 & 3,02 \\
\hline 1 & 1 & 158,0 & 81,7 & 37,399 & 7,869 & 17,66 & 1340 & 1080 & 3,88 \\
\hline 1 & 2 & 165,0 & 97,8 & 43,901 & 8,124 & 18,58 & 980 & 780 & 4,37 \\
\hline 1 & 3 & 183,0 & 107,5 & 53,002 & 8,584 & 18,23 & 840 & 780 & 5,37 \\
\hline 1 & 4 & 190,0 & 140,4 & 50,120 & 7,341 & 21,71 & 460 & 780 & 7,51 \\
\hline 2 & 0 & 141,0 & 75,1 & 21,835 & 5,665 & 13,93 & 1180 & 960 & 3,02 \\
\hline 2 & 1 & 150,0 & 80,3 & 26,845 & 6,353 & 15,28 & 1160 & 940 & 3,88 \\
\hline 2 & 2 & 166,0 & 87,5 & 35,951 & 7,590 & 17,07 & 1160 & 940 & 4,37 \\
\hline 2 & 3 & 189,5 & 97,9 & 52,149 & 8,652 & 19,06 & 1040 & 940 & 5,37 \\
\hline 2 & 4 & 212,0 & 122,7 & 52,824 & 8,289 & 21,77 & 660 & 920 & 7,51 \\
\hline 3 & 0 & 66,0 & 45,4 & 5,748 & 3,582 & 8,82 & 2140 & 2140 & 2,02 \\
\hline 3 & 1 & 79,0 & 55,2 & 12,570 & 5,265 & 10,54 & 2120 & 2120 & 2,88 \\
\hline 3 & 2 & 93,0 & 64,3 & 23,457 & 7,186 & 12,43 & 2120 & 2120 & 3,23 \\
\hline 3 & 3 & 140,0 & 75,6 & 38,069 & 10,086 & 13,84 & 2120 & 2120 & 4,37 \\
\hline 4 & 0 & 80,0 & 52,2 & 9,968 & 3,721 & 10,12 & 1680 & 1680 & 3,02 \\
\hline 4 & 1 & 92,0 & 57,3 & 13,246 & 4,499 & 10,76 & 1680 & 1680 & 3,88 \\
\hline 4 & 2 & 108,0 & 67,3 & 22,606 & 6,210 & 11,94 & 1680 & 1680 & 4,23 \\
\hline 4 & 3 & 135,0 & 78,8 & 42,412 & 8,446 & 15,10 & 1660 & 1680 & 5,37 \\
\hline 5 & 0 & 181,0 & 69,8 & 30,652 & 9,150 & 12,49 & 2220 & 2220 & 2,02 \\
\hline 5 & 1 & 182,0 & 71,0 & 31,288 & 9,449 & 12,55 & 2220 & 2220 & 2,88 \\
\hline 5 & 2 & 189,0 & 74,7 & 39,438 & 10,454 & 13,99 & 2220 & 2220 & 3,23 \\
\hline 5 & 3 & 191,5 & 79,7 & 60,168 & 11,916 & 13,53 & 2220 & 2220 & 4,37 \\
\hline 5 & 4 & 20,2 & 7,8 & 0,017 & 0,165 & 15,79 & 3040 & 1060 & 6,65 \\
\hline 6 & 0 & 137,0 & 85,1 & 33,100 & 8,670 & 11,06 & 1400 & 720 & 4,13 \\
\hline 6 & 1 & 138,0 & 85,7 & 30,836 & 8,665 & 12,44 & 1380 & 720 & 4,88 \\
\hline 6 & 2 & 146,0 & 92,3 & 42,475 & 10,078 & 13,45 & 1380 & 720 & 5,23 \\
\hline 6 & 3 & 158,0 & 102,3 & 55,263 & 12,464 & 13,41 & 1380 & 720 & 6,37 \\
\hline 7 & 0 & 132,0 & 74,8 & 45,142 & 10,238 & 16,24 & 2220 & 1280 & 4,13 \\
\hline 7 & 1 & 142,0 & 78,5 & 52,808 & 11,309 & 16,91 & 2220 & 1280 & 4,88 \\
\hline 7 & 2 & 155,0 & 85,1 & 72,313 & 13,407 & 19,60 & 2220 & 1280 & 5,23 \\
\hline 7 & 3 & 170,0 & 96,0 & 87,114 & 15,876 & 16,74 & 2020 & 1280 & 6,37 \\
\hline 8 & 0 & 115,0 & 53,8 & 15,386 & 6,009 & 11,97 & 2380 & 1340 & 3,13 \\
\hline 8 & 1 & 123,0 & 57,5 & 21,754 & 6,871 & 13,05 & 2400 & 1380 & 3,88 \\
\hline 8 & 2 & 133,0 & 64,3 & 31,971 & 8,580 & 14,75 & 2400 & 1360 & 4,23 \\
\hline 8 & 3 & 153,0 & 74,2 & 63,812 & 11,352 & 20,85 & 2360 & 1320 & 5.37 \\
\hline 9 & 0 & 441,0 & 185,3 & 200,015 & 23,616 & 26,82 & 640 & 640 & 17.13 \\
\hline 9 & 1 & 448,0 & 189,4 & 197,240 & 23,832 & 25,98 & 620 & 620 & 17,88 \\
\hline 9 & 2 & 470,0 & 208,3 & 246,355 & 26,667 & 27,82 & 600 & 600 & 18,37 \\
\hline 9 & 3 & 501,0 & 215,1 & 278,007 & 29,338 & 30,30 & 620 & 620 & 19,37 \\
\hline
\end{tabular}

